\title{
Tornadoes in Germany 1950-2003 and their relation to particular weather conditions
}

\author{
Peter Bissolli $^{\mathrm{a}, *}$, Jürgen Grieser ${ }^{\mathrm{b}}$, Nikolai Dotzek ${ }^{\mathrm{c}}$, Marcel Welsch ${ }^{\mathrm{d}}$ \\ ${ }^{a}$ Deutscher Wetterdienst (German Meteorological Service), Kaiserleistr. 29/35, 63067 Offenbach, Germany \\ ${ }^{\mathrm{b}}$ Food and Agriculture Organization (FAO) of the UN, Viale delle Terme di Caracalla I, 00153 Roma, Italy \\ ${ }^{\mathrm{c}}$ DLR-Institut für Physik der Atmosphäre, Oberpfaffenhofen, 82234 Wessling, Germany \\ d Sollingstr. 2, 37194 Bodenfelde, Germany
}

Available online 5 January 2007

\begin{abstract}
The objective of this statistical-climatological study is to identify characteristic weather situations in which tornadoes in Germany preferably occur. Tornado reports have been taken from the TorDACH database for the period 1950-2003. Weather situations are defined by the objective weather types classification of the German Meteorological Service (DWD), described by the direction of air mass advection, the cyclonality and the humidity (precipitable water) of the troposphere. In addition the number of thunderstorm days and aerological parameters, derived from temperature and dewpoint in 850 and $500 \mathrm{hPa}$, are taken into account.

Higher frequencies of tornadoes in Germany are found in recent years 1998-2003, particularly in the years 2003 (40 tornadoes) and 2000 (warmest year in Germany since the beginning of the 20th century). There is no shift of the seasonal cycle detectable for the period 1980-2003 compared to 1950-2003 and also no shift of the intensity distribution. The majority of the tornadoes can be attributed to 3 specific weather types, all with a south-westerly advection and high humidity. This can be found for weak as well as for strong tornadoes. Anti/cyclonality in $950 \mathrm{hPa}$ reduces/enhances the tornado frequency roughly by a factor of 2 , while in $500 \mathrm{hPa}$ cyclonality shows no significant influence.

The fraction of the number of registered tornado days to the number of thunderstorm days has a maximum of one tornado in 50 thunderstorm days in the north-western part of Germany. Specific ranges of temperature and dewpoint in 850/500 hPa, which are not the highest values, are favoured for the occurrence of tornadoes.
\end{abstract}

(C) 2006 Elsevier B.V. All rights reserved.

Keywords: tornadoes; tornado climatology; weather types classification; thunderstorm days

\section{Introduction}

Tornadoes are severe convective storm phenomena on a scale of a few hundred meters only, but they can cause considerable damage to buildings and be a serious danger for daily life due to their extremely high wind

\footnotetext{
* Corresponding author. Tel.: +49 8062 0; fax: +49 80623759.

E-mail address: peter.bissolli@dwd.de (P. Bissolli).

URL: http://www.dwd.de (P. Bissolli).
}

velocity and their destructive force. They belong to those extreme weather events which have attracted much attention by the general public, but also to weather forecasters, climatologists, storm chasers and research scientists for observing, understanding, monitoring and, if possible, forecasting this phenomenon. Tornadoes are observed in most parts of the world. They are observed frequently in the USA, but recently observations also increased in Central Europe (cf. ECSS proceedings; Snow, 2001, 2003) after some decades of neglect. As 
discussed by Dotzek (2003), in the period up to World War II, tornado research was quite advanced in Europe, and Wegener (1917) had given a European climatology after providing the first useful tornado definition.

It is a core task of national meteorological services to forecast and monitor the probability of occurrence of tornadoes, to issue warnings to the public, and to perform a posteriori evaluation of the forecasts and warnings. Due to the development in meteorological research, computer and other technical facilities, and more than 50-yr experience in severe storm forecasting, a number of observational tools (e.g. Doppler radar) and model output parameters are available today for operational nowcasting and short-range prediction (Ostby, 1999). This is not the case for long-range and climate forecasts. As a tornado is a small-scale and short-lived event, it is still not possible to forecast individual tornadoes in time for longer periods. However, severe convective storms are attributed to certain weather situations, namely those leading to the main ingredients (Doswell et al., 1996) for convective initiation: instability, low-level moisture, and mesoscale lift. Thus, there is a fair chance to define largescale weather situations in which tornadoes could occur with high probability. These weather situations should be predictable several days in advance, which means they have to be defined on a larger scale than the tornadoes themselves. Certainly, many criteria of defining such a weather situation are necessary, and as long as not all details of tornado development are understood, such a list of criteria can never be complete.

Extreme events in general and tornadoes in particular are also of special importance in climatology. In the light of global warming which has been taken place especially during recent decades, the question arose immediately whether such extreme events could occur with a higher or lower frequency, extension, or intensity in the future compared to the past (IPCC, 2001). In the case of tornadoes this question is more difficult to answer than for many other extreme events, since tornadoes as a small-scale phenomenon cannot be predicted by present climate models which do not have sufficient spatial resolution. The present global climate models (general circulation models, GCM) typically have a spatial resolution between 100 and $500 \mathrm{~km}$, and even modern cloud resolving models (CRM) have a grid spacing of a few kilometers (Cole et al., 2005) which is still too coarse to resolve cloud subsystems like tornadoes and similar events.

Because of this reason it seems useful to apply statistical climatology for this problem. A first step into this direction is the classification of large-scale air mass and circulation parameters as primary conditions for tornado occurrence. For this purpose a huge number of weather types classifications are available for different scales, areas, and databases (Yarnal et al., 2001; Tveito and Ustrnul, 2003). To our knowledge, there is no weather types classification, at least for the area of Germany or Central Europe, which has been developed especially for tornado analysis. Thus, existing appropriate weather types classifications have to be related to reliable tornado data to define possible weather types where tornadoes appear more frequently than for other synoptical situations.

To also have a look at a possible intensity change of tornadoes, intensity data have to be included into such a statistical analysis. Intensity data are very important for risk assessment of tornadoes (Brooks and Doswell, 2001a) which is required by e.g. insurance companies for estimating future damage (Dotzek 2002). For quantifying the intensity of tornadoes, several scale classifications were developed. Of them, the Fujita scale (e. g. Fujita, 1981) is most widely used. This F-scale which is applied also in this paper was defined originally by a continuous function of the wind speed of tornadoes, but in practice, discrete intensity classes are used, and the estimation of the tornado intensity considers the maximum damage which occurs during such an event, since the tornado wind speed usually is not measured. This issue has been discussed in various papers (e.g. Doswell and Burgess, 1988; Fujita, 1992; Dotzek et al., 2000; Brooks and Doswell, 2001b; Dotzek, 2001; Hubrig, 2004).

The purpose of this paper is to relate data of the objective weather types classification of the German Meteorological Service (Deutscher Wetterdienst, DWD), which is a classification of air masses and circulation indices on the synoptical scale, to the frequency of tornadoes of different intensity. If the tornado occurrence, or at least a high percentage of it, can be attributed to a small number of characteristic weather or circulation types, the results can be taken to quantify the probability of tornado occurrence for future synoptical situations which can be monitored and forecasted more easily than a tornado itself.

The paper is organised as follows: Section 2 gives an overview of the tornado observations and the synoptic weather type classification, Section 3.1 the results of a frequency analysis for a tornado climatology 19502003, Section 3.2 shows the relations between tornado frequency and the occurrence of weather types. For investigating also other appropriate meteorological conditions, in Section 3.3 we analysed in addition the relation of tornadoes to thunderstorm days and in Section 3.4 to aerological parameters such as temperature and 
dewpoint in 850 and $500 \mathrm{hPa}$. A discussion follows in Section 4 and conclusions are drawn in Section 5.

\section{Data}

\subsection{Tornado reports}

Tornado reports for Germany are taken from the database of the TorDACH network (www.tordach.org). The analysis has been restricted to the area of Germany because the weather types classification, discussed in the next section, refers to this area. Note that in the present paper, waterspout tornadoes (either landfalling or not) are not included in the analysis. Several studies have already been based on this data source (e. g. Dotzek, 2001; Dotzek et al., 2003; Feuerstein et al., 2005). Such tornado reports are either based on actual observations of the events occurring, or on a posteriori damage surveys which allow classifying the damage as tornadic. Tornado report databases of this type have been created and augmented for more than half a century and successfully been applied for climatological purposes (cf. Brooks and Doswell, 2001b). To a very large extent, tornado reports can be regarded as objective information on the actual events, even though such data cannot be $100 \%$ complete and involve some inherent uncertainty, e.g. in the intensity ratings (cf. the recent quality assessment of the US tornado data by Verbout et al., 2006). However, actual tornado reports are far superior to deriving tornado occurrence from remote sensing data, like Doppler radar or satellites, for which no unambiguous diagnostic algorithms exist to decide if a thunderstorm is tornadic.

Similar to the US tornado database, the TorDACH data for Germany contain detailed information of the events such as date, time and location of occurrence, type of the event (tornado, waterspout, downburst etc.), the intensity (e.g. F-scale), additional meteorological information if remarkable (e.g. air temperature, precipitation amount or hail sizes) and descriptions about the source of observation. The reports are made available on the web site www.tordach.org/de/ to inform the public and to encourage feedback on reported events. Once a year, additional detailed quality control of all reports from the previous year (and any updates of earlier reports) is performed by the TorDACH network to keep the data on high quality for climatological investigations.

During preparation of this paper, the quality control was carried out until the year 2003 (database version V 1.4), thus, data after this year have not been included here. The starting year of this analysis is 1950 , to be consistent with other studies (e. g. Schmitz, 2005) and to take the same start date like most studies of US tornado climatology. As the time series of the weather types classification (see Section 2.2) only begins with the year 1980 , here only $24 \mathrm{yr}$ are available for comparison. It has to be emphasised that tornado time series are unlikely to be complete, since the compilation only consists of tornadoes which have been reported. There are certainly a lot which have occurred but never been observed, and from these which have been observed, not all have been reported. This leads to an underreporting of the absolute number of tornadoes. Therefore, no absolute values of probabilities should be drawn from these data. The underreporting is also a function of population density and therefore has a spatial structure. Furthermore, the underreporting has to be regarded as time dependent. As public tornado awareness has increased recently in Central Europe, there have been more tornadoes reported in the recent past compared to the years before, but not necessarily more occurred. However, there is no reason for the hypothesis that the underreporting depends on weather type or season. The database therefore is adequate for the investigation of relative values of probabilities by comparing seasons or weather types.

Tornadoes can be treated as individual events. In this case a record of events is to be analysed. However, since on some days more than one tornado occurred, a record of tornado days is used as well. Herein, a tornado day is defined as a day with at least one tornado occurring. Obviously, the tornado day concept is less prone to underreporting effects, and hence a more robust quantity than the number of tornadoes on a given day. Thus, tornado day statistics are especially applied for assessing the probability of tornado occurrence in relation to weather types, since also the weather types are attributed to days, not to single events.

\subsection{Weather types classification}

At the DWD, an objective weather types classification has been developed for climatological applications. This classification has been described in detail by Bissolli and Dittmann (2001), so only a brief overview is given here.

The basis for this classification is the current operational numerical large-scale forecast model of the DWD. Presently, the model GME (Global Model extended) is used. It has a horizontal resolution of about $40 \mathrm{~km}$. The classification criteria are the following:

- Advection of air masses, described by the horizontal wind components in $700 \mathrm{hPa}$, 
Table 1

The objective weather types of the German Meteorological Service, DWD

\begin{tabular}{|c|c|c|c|c|c|}
\hline No. & Label & $\begin{array}{l}\text { Wind } \\
\text { direction }\end{array}$ & $\begin{array}{l}\text { Cyclonality } \\
\text { in } 950 \mathrm{hPa}\end{array}$ & $\begin{array}{l}\text { Cyclonality } \\
\text { in } 500 \mathrm{hPa}\end{array}$ & $\begin{array}{l}\text { Humidity } \\
\text { of the } \\
\text { troposphere }\end{array}$ \\
\hline 1 & XXAAD & $\begin{array}{l}\text { No } \\
\text { prevailing } \\
\text { direction }\end{array}$ & Anticyclonic & Anticyclonic & Dry \\
\hline 2 & NEAAD & Northeast & Anticyclonic & Anticyclonic & Dry \\
\hline 3 & SEAAD & Southeast & Anticyclonic & Anticyclonic & Dry \\
\hline 4 & SWAAD & Southeast & Anticyclonic & Anticyclonic & Dry \\
\hline 5 & NWAAD & Northwest & Anticyclonic & Anticyclonic & Dry \\
\hline 6 & XXAAW & $\begin{array}{l}\text { No } \\
\text { prevailing } \\
\text { direction }\end{array}$ & Anticyclonic & Anticyclonic & Wet \\
\hline 7 & NEAAW & Northeast & Anticyclonic & Anticyclonic & Wet \\
\hline 8 & SEAAW & Southeast & Anticyclonic & Anticyclonic & Wet \\
\hline 9 & SWAAW & Southwest & Anticyclonic & Anticyclonic & Wet \\
\hline 10 & NWAAW & Northwest & Anticyclonic & Anticyclonic & Wet \\
\hline 11 & XXACD & $\begin{array}{l}\text { No } \\
\text { prevailing } \\
\text { direction }\end{array}$ & Anticyclonic & Cyclonic & Dry \\
\hline 12 & NEACD & Northeast & Anticyclonic & Cyclonic & Dry \\
\hline 13 & SEACD & Southeast & Anticyclonic & Cyclonic & Dry \\
\hline 14 & SWACD & Southwest & Anticyclonic & Cyclonic & Dry \\
\hline 15 & NWACD & Northwest & Anticyclonic & Cyclonic & Dry \\
\hline 16 & XXACW & $\begin{array}{l}\text { No } \\
\text { prevailing } \\
\text { direction }\end{array}$ & Anticyclonic & Cyclonic & Wet \\
\hline 17 & NEACW & Northwest & Anticyclonic & Cyclonic & Wet \\
\hline 18 & SEACW & Southeast & Anticyclonic & Cyclonic & Wet \\
\hline 19 & SWACW & Southwest & Anticyclonic & Cyclonic & Wet \\
\hline 20 & NWACW & Northwest & Anticyclonic & Cyclonic & Wet \\
\hline 21 & XXCAD & $\begin{array}{l}\text { No } \\
\text { prevailing } \\
\text { direction }\end{array}$ & Cyclonic & Anticyclonic & Dry \\
\hline 22 & NECAD & Northeast & Cyclonic & Anticyclonic & Dry \\
\hline 23 & SECAD & Southeast & Cyclonic & Anticyclonic & Dry \\
\hline 24 & SWCAD & Southwest & Cyclonic & Anticyclonic & Dry \\
\hline 25 & NWCAD & Northwest & Cyclonic & Anticyclonic & Dry \\
\hline 26 & XXCAW & $\begin{array}{l}\text { No } \\
\text { prevailing } \\
\text { direction }\end{array}$ & Cyclonic & Anticyclonic & Wet \\
\hline 27 & NECAW & Northeast & Cyclonic & Anticyclonic & Wet \\
\hline 28 & SECAW & Southeast & Cyclonic & Anticyclonic & Wet \\
\hline 29 & SWCAW & Southwest & Cyclonic & Anticyclonic & Wet \\
\hline 30 & NWCAW & Northwest & Cyclonic & Anticyclonic & Wet \\
\hline 31 & XXCCD & $\begin{array}{l}\text { No } \\
\text { prevailing } \\
\text { direction }\end{array}$ & Cyclonic & Cyclonic & Dry \\
\hline 32 & NECCD & Northeast & Cyclonic & Cyclonic & Dry \\
\hline 33 & SECCD & Southeast & Cyclonic & Cyclonic & Dry \\
\hline 34 & SWCCD & Southwest & Cyclonic & Cyclonic & Dry \\
\hline 35 & NWCCD & Northwest & Cyclonic & Cyclonic & Dry \\
\hline 36 & $\mathrm{XXCCW}$ & $\begin{array}{l}\text { No } \\
\text { prevailing } \\
\text { direction }\end{array}$ & Cyclonic & Cyclonic & Wet \\
\hline 37 & NECCW & Northeast & Cyclonic & Cyclonic & Wet \\
\hline 38 & SECCW & Southeast & Cyclonic & Cyclonic & Wet \\
\hline 39 & SWCCW & Southwest & Cyclonic & Cyclonic & Wet \\
\hline
\end{tabular}

Table 1 (continued)

\begin{tabular}{lllll}
\hline No. Label & $\begin{array}{l}\text { Wind } \\
\text { direction }\end{array}$ & $\begin{array}{l}\text { Cyclonality } \\
\text { in } 950 \mathrm{hPa}\end{array}$ & $\begin{array}{l}\text { Cyclonality } \\
\text { in } 500 \mathrm{hPa}\end{array}$ & $\begin{array}{l}\text { Humidity } \\
\text { of the } \\
\text { troposphere }\end{array}$ \\
\hline $40 \quad$ NWCCW & Northwest & Cyclonic & Cyclonic & Wet \\
\hline
\end{tabular}

- Cyclonality, described by the second spatial derivative of the geopotential $\left(\nabla^{2} \Phi\right)$ in two levels (950 and $500 \mathrm{hPa}$ ),

- Humidity, described by the precipitable water, derived from temperature and humidity fields in 5 levels within the troposphere.

The classification area comprises Germany and adjacent regions (northern edge in $55^{\circ} \mathrm{N}$, from $2^{\circ} \mathrm{E}$ to $18^{\circ} \mathrm{E}$, southern edge in $45^{\circ} \mathrm{N}$, from $4^{\circ} \mathrm{E}$ to $16^{\circ} \mathrm{E}$ ). Thus, the classification refers to the synoptical scale, which means the air masses are subjects of the classification.

The classification result yields the following classes (types):

- 5 classes of advection: northeast (NE), southeast (SE), southwest (SW), northwest (NW), no prevailing direction (XX). XX is given when none of the $90^{\circ}$ wind direction sectors $0-90^{\circ}, 10-100^{\circ}, 20-110^{\circ}, \ldots$, $350-80^{\circ}$ contains at least $2 / 3$ of all GME model gridpoints.

- 2 classes of cyclonality in each level (950 and $500 \mathrm{hPa})$ : cyclonic $\left(\mathrm{C} ; \nabla^{2} \Phi \geq 0\right)$ or anticyclonic $\left(\mathrm{A} ; \nabla^{2} \Phi<0\right)$.

- 2 classes of humidity: dry (D; precipitable water amount is lower than the monthly climate mean 1981-2000), wet (W; precipitable water amount is equal or higher than the monthly climate mean 19812000). The period 1981-2000 is a fixed climate reference which is used for the whole time series.

Altogether, these are 40 types labelled by a 5-letter abbreviation. The first two letters indicate the direction of the advection, the third and fourth letter the cyclonality in 950 and $500 \mathrm{hPa}$, respectively, and the 5th letter the humidity. For example, NWACD means: northwest, anticyclonic in $950 \mathrm{hPa}$, cyclonic in $500 \mathrm{hPa}$, dry. A list of the 40 types is given in Table 1 .

The classification is carried out once a day for the numerical 12:00 UTC analysis of the GME model, and also for the forecast fields (forecast time up to $7 \mathrm{~d}$ ). A time series of daily classification data for the 12:00 UTC analysis is available starting in July 1979; this means it covers 27 yr now. In this study the 24-yr period 1980 2003 (only 12:00 UTC analysis) has been used to have 24 complete years (apart from a few gaps) for this analysis. 


\subsection{Thunderstorm days and aerological information}

For analysis of the relation between thunderstorm and tornado occurrence the number of thunderstorm days (days with audible thunder at an observing station) for the period 1950-2003 of all available climate stations has been taken from the database of the DWD. Only those data have been considered which cover nearly the whole period. For all stations the number of thunderstorm days has been normalised as average number of thunderstorms per yr to take the different numbers of years with available data for each station into account. In total there are 49 stations with complete or nearly complete time series for the period 1950-2003 available, for the subperiod 1980-2003 this number increases to 110 stations.

For analysing the relation of tornadoes to additional atmospheric parameters, temperature and dewpoint data in 850 and $500 \mathrm{hPa}$ at the aerological station Essen in the western part of Germany $\left(51^{\circ} 24^{\prime} \mathrm{N}, 06^{\circ} 58^{\prime} \mathrm{E}\right)$ are taken from the DWD database. This station has been selected because it is located in a region with many tornado reports (see Section 3.2). Unfortunately this station did not exist in 1950 already, so this analysis is restricted to the shorter period 1980-2003, to be consistent to the weather types statistics.

\section{Results}

\subsection{Tornado climatology 1950-2003}

Some climatological analyses of TorDACH tornado data, especially for the years since 1950 to facilitate comparison to the USA, have already been published on the TorDACH website and in various papers (e.g. Schmitz, 2005; Dotzek et al., 2005).

In this period, in particular after the year 1990, the number of reported tornadoes is higher than before 1950 . Also the warmest years in Germany since the beginning of the 20th century occurred mostly in this recent period, culminating in the warmest year in Germany 2000 and the warmest summer 2003, as reported by monthly climate monitoring results of the DWD (www.dwd.de/ en/FundE/Klima/KLIS/prod/monitoring/einf_txt1.htm). Therefore, some climatological results of a univariate analysis of the tornado data are presented here.

Fig. 1 shows the time series of the annual frequency of tornado reports and tornado days in Germany (all intensities) for this period. During most of the period, this frequency was below 20 tornadoes over land per yr, in many cases even less than 10. In the year 1991 no tornadoes at all were reported. High frequencies of 25 or more tornadoes have all occurred in the recent $6-\mathrm{yr}$ period 1998-2003. However, it has to be considered that for the time before the reunification of West and East Germany in 1990 still a lot of East German events are not known. On the other hand it is remarkable that the highest frequencies of tornadoes in the investigation period occurred in the years 2003 (40 tornadoes) and in 2000 (31 tornadoes, warmest year in Germany). Especially the 2003 tornadoes from May-July were coupled to an unusually large number of synoptic settings with moist, warm, south-westerly flow. For the whole period 1950-2003, 468 tornadoes (9 tornadoes per yr on average) have been reported in the database, which means that more than $15 \%$ of this number occurred in the exceptional years 2000 and 2003. In the recent period 1980-2003 there were 290 tornadoes (12 per yr

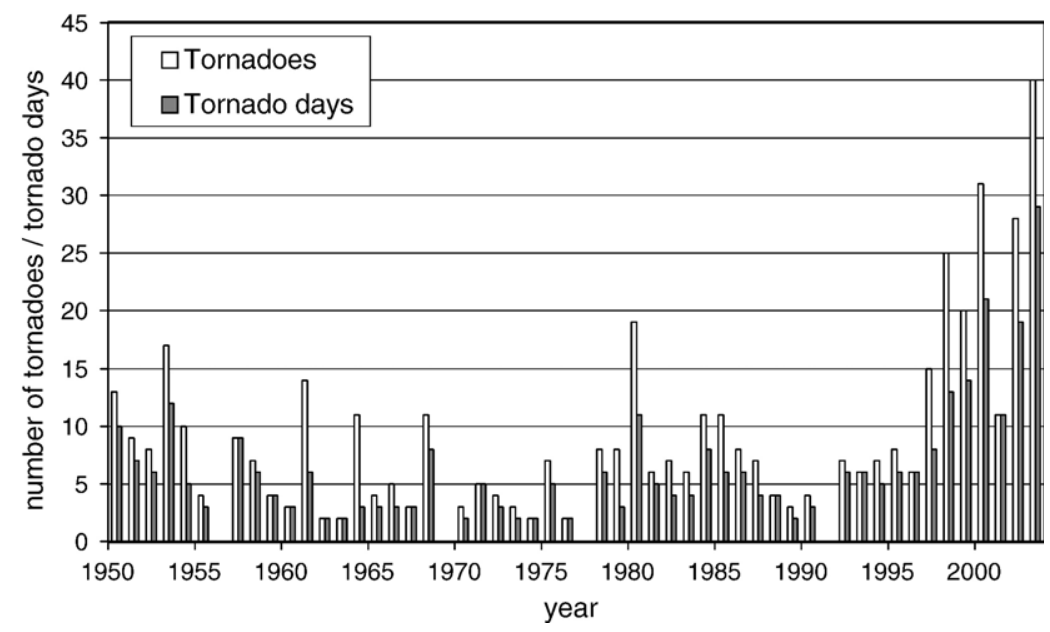

Fig. 1. Annual tornado reports and number of tornado days in Germany, 1950-2003. 
on average), more than half of them (155) in the recent years 1998-2003 (average of 26 per yr). For comparison, about 1200 tornadoes occur per yr in the USA (1990s), and Dotzek (2003) gave the following estimates for Europe: 169 tornadoes per yr are observed over land. If the tornadoes over water are included, too, more than 300 tornadoes are to be observed in Europe. The estimated real number of tornadoes in Europe (and thus also in Germany), however, is expected to be much higher.

The number of tornado days is in many years lower than the number of tornadoes itself, which means that it happens quite often, that more than one tornado appears on $1 \mathrm{~d}$, especially in years with a high tornado frequency. However, also here the highest numbers can be found for the recent years and in particular in the years 2003 (29 d) and 2000 (21 d). There were $326 \mathrm{~d}$ with reported tornadoes during the whole period 1950-2003 (6 per yr on average), $201 \mathrm{~d}$ in 1980-2003 (8 per yr) and $107 \mathrm{~d}$ in 1998-2003 (18 per yr). In summary, a remarkable increase of reported tornadoes as well as of tornado days with time can be found for Germany, in particular for the recent years.

The time series of the tornado intensities is shown in Fig. 2. In 110 cases $(23.5 \%)$ of the data sample, no intensity has been reported, so these are not considered in Fig. 2. The remaining data are distributed to the Fujita scale numbers $\mathrm{F}-1$ to $\mathrm{F} 4$. However, there were only three sub-critical $\mathrm{F}-1$ cases during the whole period, all in the year 2003. The majority of recorded tornadoes in Germany (55\%) are weak ones (F1 or less), but it has to be considered that an F1 tornado can reach wind velocities up to more than $180 \mathrm{~km} / \mathrm{h}$ which has to be regarded as serious. Further $18 \%$ are F2 tornadoes which are classified as strong ones with velocities of up to more than $250 \mathrm{~km} / \mathrm{h}$. Thirteen tornadoes are even stronger F3 events, one in 2001 and one again in 2003, the others all before 1980. From the highest scale numbers F4 and F5, named as violent, only one F4 tornado has been reported for the investigation period. This is the well-known "Pforzheim tornado" which occurred on 10 July 1968 in the town Pforzheim in the Black Forest area in southwest Germany (e. g. Nestle, 1968; Fulks, 1969). This event confirmed again that even such extreme violent tornadoes are possible in Germany.

For reasons of simplicity and to have a larger sample, those tornadoes with Fujita scales F0 and F1 are summarised as weak tornadoes (including the $3 \mathrm{~F}-1$ reports) and those with F2, F3 and F4 as significant ones in Fig. 2. This graph shows the increase of reported tornadoes in recent years again, most pronounced for weak tornadoes. It might be possible that particularly in earlier years weak tornadoes were just overlooked or misclassified as non-tornadic storm damage. As shown by Dotzek et al. (2005), a similar increase in tornado reports up to F2 took place in the USA after 1953. On the other hand, the highest number of events occurred in the exceptional year 2003 for weak as well as for strong tornadoes.

The seasonal cycles for the investigation periods 1950-2003 and 1980-2003 are displayed in Fig. 3 by the frequency distribution of tornadoes to all months of the year. The maximum frequency can be found for both periods in July with $23 \%$ and $24 \%$, respectively, of all tornadoes of the whole period. The main tornado season is in the summer half year from May to September, especially in the summer months June to August, while in the winter half year from October to April the

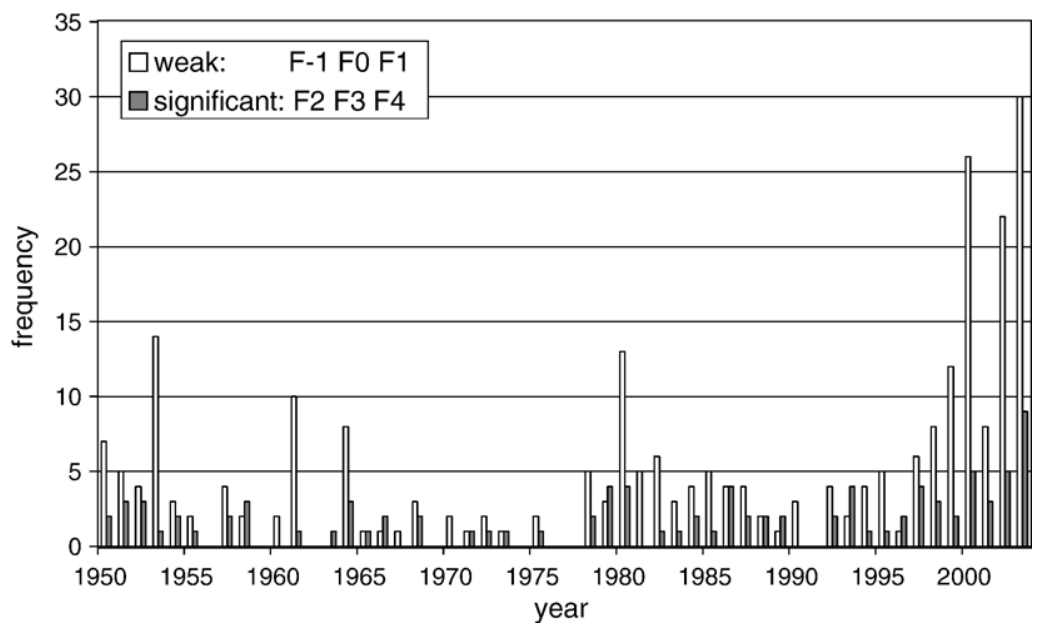

Fig. 2. Tornado reports in Germany 1950-2003 for weak (Fujita scale F - 1, F0, F1) and significant (F2-F4) tornadoes. 


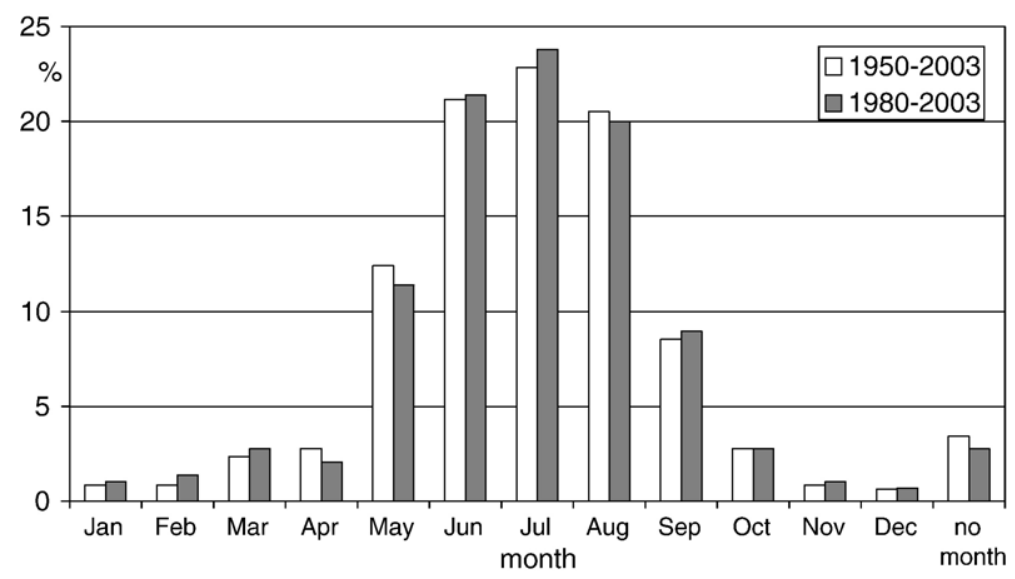

Fig. 3. Tornado reports in Germany 1950-2003 compared to 1980-2003 for each calendar month.

frequencies are all quite small. This result is to be expected since also the convective activity and the thunderstorm frequency are concentrated mainly to the summer months. Moreover, it can be seen that the seasonal cycle of the period 1980-2003 is very similar to that of 1950-2003. Thus, this distribution looks reasonable from a meteorological point of view and is also stationary with time within about the second half of the 20th century, in contrast to the absolute annual frequencies as displayed in Fig. 1.

\subsection{Tornadoes in relation to weather types}

Here, results of the frequency distribution of tornadoes to various weather types are presented. The sample consists of 275 tornadoes recorded on $193 \mathrm{~d}$ for which the exact day of their occurrence is known. Only those tornadoes can be linked to daily weather types. However, the number of tornadoes without exact days is quite small, so this effect does not affect the representativeness of the results.

Fig. 4 shows the frequency distribution of this sample to the 40 weather types of the objective weather types classification of the DWD. It is apparent that the majority of the tornadoes occurred for the 3 types SWAAW (southwest, anticyclonic in 950 and $500 \mathrm{hPa}$, wet), SWCAW (southwest, cyclonic in $950 \mathrm{hPa}$, anticyclonic in $500 \mathrm{hPa}$, wet), and SWCCW (southwest, cyclonic in 950 and $500 \mathrm{hPa}$, wet; see Table 1 for the other abbreviations of the weather types). These 3 types together yield $55 \%$ of the whole sample, $26 \%$ can be attributed to type SWCAW only. These types are all characterised by a south-westerly advection and a high tropospheric humidity, but they can be cyclonic as well as anticyclonic near the surface and in the upper atmo- sphere. From all the 40 types, tornadoes are only to be found for 25 types. The other 15 types obviously either occur very rarely in general or they do not provide the meteorological conditions for tornado development.

The three major "tornado weather types" SWAAW, SWCAW, and SWCCW have been further analysed in respect to the tornado intensities (Fig. 5). It can be seen that the intensity distributions for these types look more or less similar to the corresponding distribution for all types for both periods 1950-2003 and 1980-2003, at least concerning their general shape. The only exception is the comparably low number of F3 events for 19802003. Some more, but unreported F3 tornadoes could have occurred in the 1980s or 1990s. On the other hand, the similarity of these frequency distributions means that there is no preference for weaker or stronger tornadoes for any of these weather types compared to the whole sample.

It has been proposed in the literature that the F-scale ratings reproduce a roughly lin-log probability density (Brooks, 2000; Brooks and Doswell, 2001a,b), except for the very weak F0 or even negative-F tornadoes. In recent papers by Dotzek et al. $(2003,2005)$ and Feuerstein et al. (2005), it has turned out that the Weibull function describes better the tornado intensity distribution than an exponential distribution, especially for very weak and very strong tornadoes.

The higher tornado frequency for weather types with southwest advection and high humidity which has been revealed in Fig. 4 can be further refined by using a higher resolution of these parameters as given by the 5 advection and the 2 humidity types. In Fig. 6 the wind direction sector data of the objective weather types classification are used for frequency analysis. Each day of the investigation period has a main wind direction 


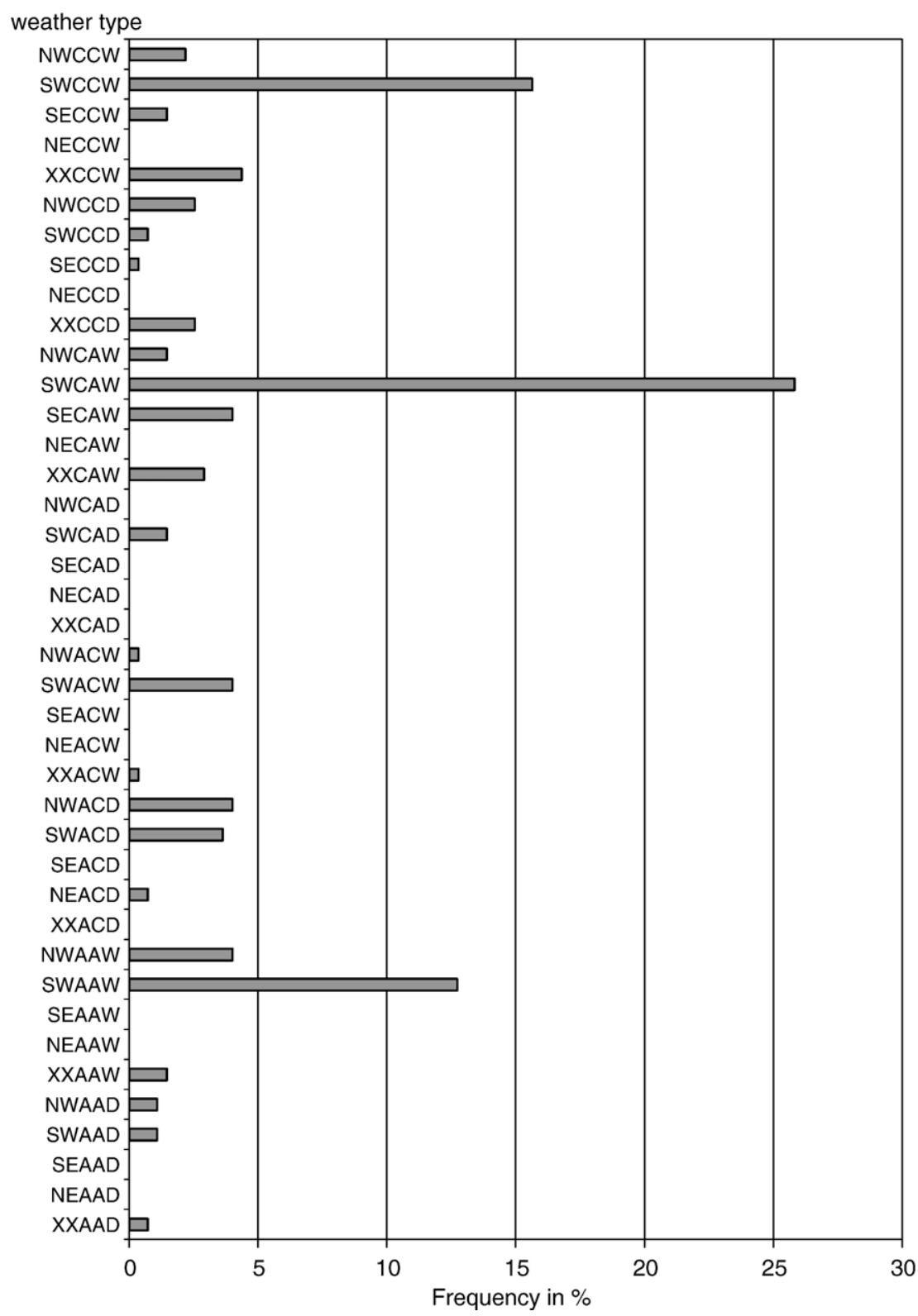

Fig. 4. Frequency distribution of tornadoes in Germany 1980-2003 to the objective weather types. Abbreviations of weather types see Table 1.

(majority of GME model gridpoints) in one of the overlapping wind sector intervals $0-90^{\circ}, 10-100^{\circ}, \ldots$, $350-80^{\circ}$, so each tornado event which is attributed to a defined day could also be related to one of the wind sectors. The frequency distribution of tornadoes to each of these wind sectors is displayed in Fig. 6. To have a sufficient sample size, these 36 wind sectors are summarised to 8 groups of sectors. It can be seen from this figure that the maximum frequencies can be found in the range $180-270^{\circ}$, particularly $225-270^{\circ}$ (central wind direction of the sectors) which means again a preferred southwest advection with a tendency to westerly directions. This distribution has been further refined using $20^{\circ}$ intervals instead of $45^{\circ}$ intervals. The maximum frequency is in the interval $240-260^{\circ}$, but there are also high frequencies in the ranges $220-240^{\circ}$ and $200-220^{\circ}$. In summary the preferred wind direction in $700 \mathrm{hPa}$ can be given in the range between 220 and $260^{\circ}$.

The weather types classification also provides the daily values of the precipitable water which serve as criteria for the humidity classification dry/wet. The corresponding frequency distribution (not shown) reveals 


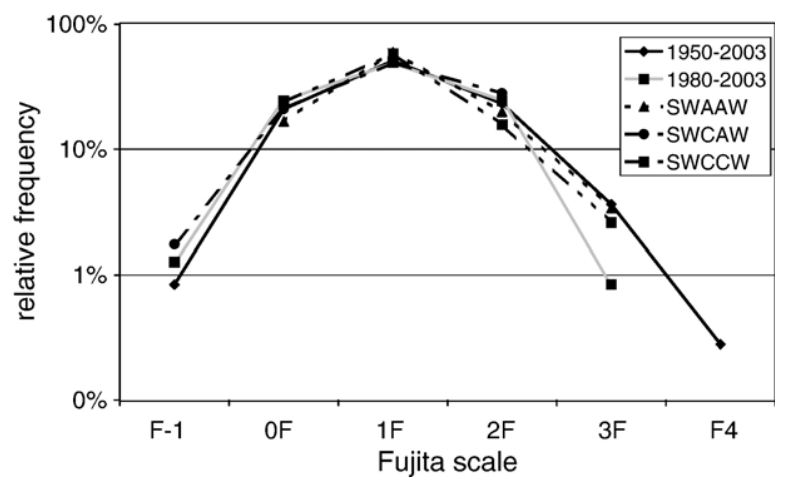

Fig. 5. Tornado intensity distributions for the periods 1950-2003 and 1980-2003, and for the weather types SWAAW, SWCAW and SWCCW, list of weather types see Table 1.

that for most tornadoes the precipitable water is between 15 and $25 \mathrm{~mm}$, without any clear dependency on the intensity of tornadoes. For comparison: the climate mean (threshold between dry and wet types) for July and August is $21 \mathrm{~mm}$, for June $19 \mathrm{~mm}$, for September $18 \mathrm{~mm}$, for May $15 \mathrm{~mm}$. Thus, there are mostly wet, but no extreme precipitable water values required for tornado development. On the other hand, also for very dry or very wet conditions $(<10$ or $>30 \mathrm{~mm})$ tornadoes are possible.

The 275 reported and dated tornadoes within the 24-yr period occurred on $193 \mathrm{~d}$. For $43 \mathrm{~d}$ more than 1 tornado is registered. Twenty-six of these days have 2 tornado registrations. And a maximum daily number of 6 tornadoes is registered for 17 August 2000. This strongly indicates that there are particular weather situations prone to produce tornadoes. Thus the question arises whether certain weather types show a significant increase or decrease in tornado frequency compared to the expected number of reported tornadoes $E\left(d_{\mathrm{T}}\right)$ for this weather type.
In order to address this question it has to be taken into account that some weather types occur very often and others are quite rare.

The null hypothesis therefore should be formulated such that the frequency of tornado occurrences is independent from the occurrence of weather types. In this case the expected number of reported tornadoes $E\left(d_{\mathrm{T}}\right)$ given a certain weather type depends only on the overall number of days of this weather type. The realised number of tornado days $d_{\mathrm{T}}$ at a certain weather type, however, can be between zero and the number of days that weather type occurred. For each weather type $d_{\mathrm{T}}$ follows a binomial distribution given the null hypothesis. Therefore, the binomial distribution can be used to test whether the ratio $d_{\mathrm{T}} / E\left(d_{\mathrm{T}}\right)$ differs significantly from unity for the observed number of reported tornadoes of each weather type.

The ratio $d_{\mathrm{T}} / E\left(d_{\mathrm{T}}\right)$ is presented in Fig. 7 for all weather types. Significant ratios are found for the weather types SWAAW, SECAW, SWCAW, XXCCW, and SWCCW. These 5 weather types cover about $25 \%$ of all days, but nearly $60 \%$ of tornado days (114 out of 193 ) are registered by these weather types. The frequency of tornadoes compared to its expected frequency is increased by a factor of 3 for the weather type SWCAW. This type happened to occur about $25 \mathrm{~d}$ a yr. One in $15 \mathrm{~d}$ of this weather type is a tornado day. Ninety-eight of the 193 tornado days happened at SWAAW, SWCAW or SWCCW. This is more than $50 \%$. It clearly shows that south-westerly advection and wet classes play a dominant role.

On the other hand, 6 weather types show a significant decrease in tornado frequency. All these types have anticyclonality at the $950 \mathrm{hPa}$ level in common. They cover 2907 d (30\%) with 15 tornado days. For 15 classes no days with tornadoes are observed. They cover $961 \mathrm{~d}$, i.e. about $11 \%$ of the period of observation.

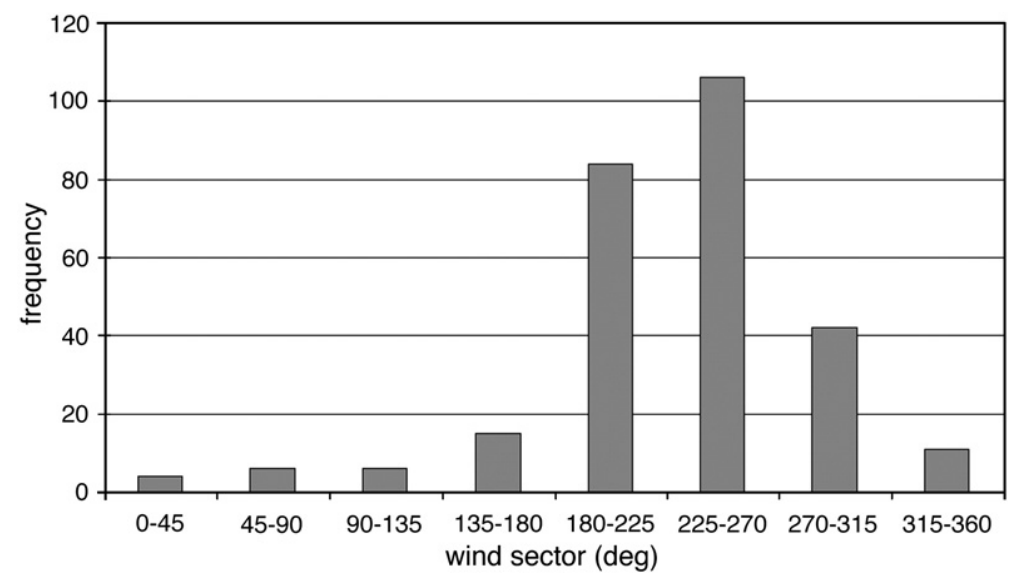

Fig. 6. Tornado frequency to wind sectors of the objective weather types classification ( $45^{\circ}$ intervals). 


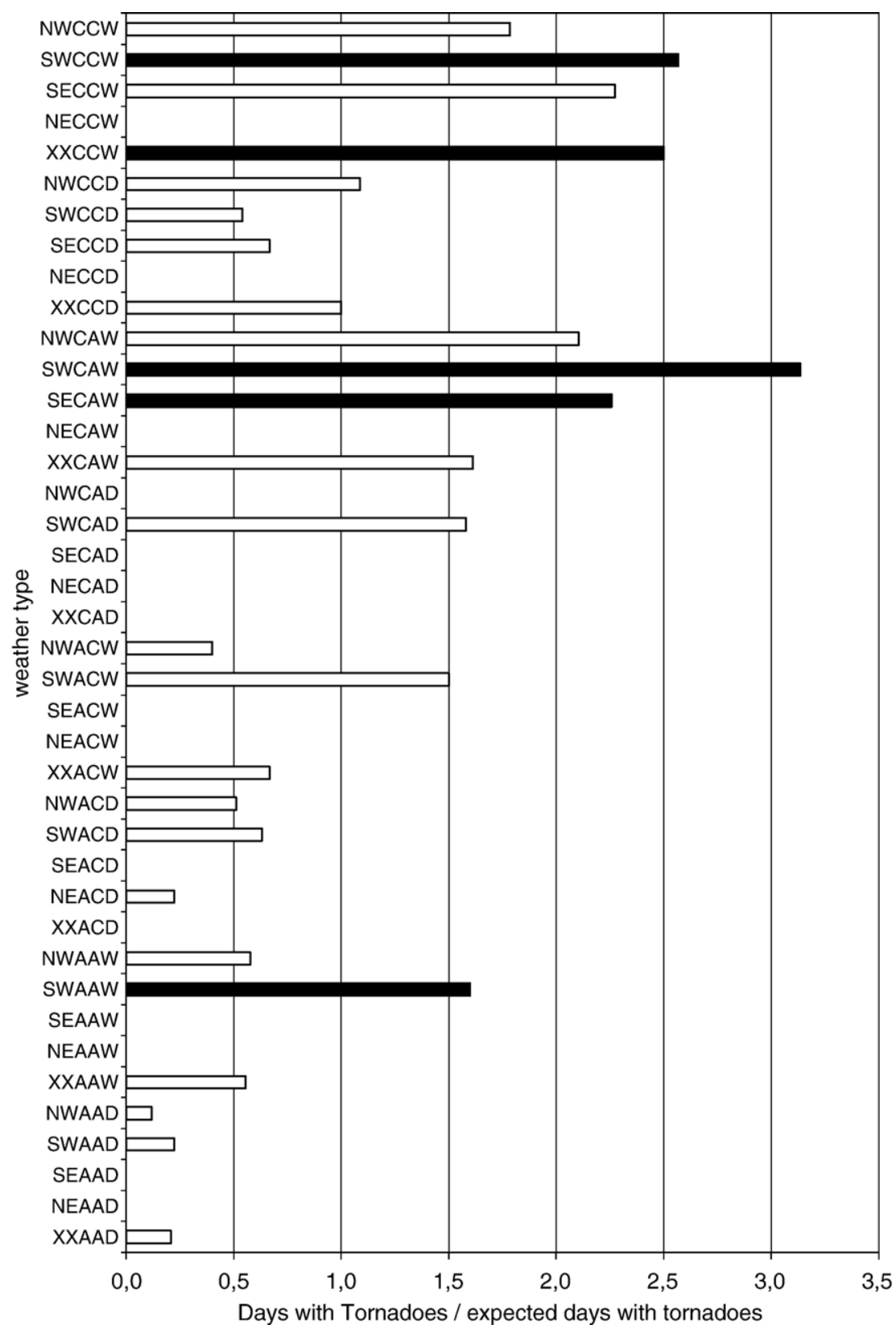

Fig. 7. Number of days with tornadoes in relation to the expected number of tornado days. Black bars indicate those types with significant (95\%) high number of tornadoes compared to the expected frequency. List of weather types see Table 1.

Further information can be drawn from grouping the weather types to classes. This leads to higher sample sizes for combined classes. Again significance tests are performed leading to the following results: all northern, north-western and north-eastern classes show significantly reduced tornado frequency. Grouping with respect to cyclonality in the $950 \mathrm{hPa}$ level shows that anticyclonality reduces the tornado frequency by factor $2(55 \%)$ while cyclonality at this level enhances the frequency by roughly the same factor (194\%). Cyclonality in the $500 \mathrm{hPa}$ level shows no significant influence. For the class of all dry types the tornado frequency is significantly reduced to $37 \%$ while it is significantly increased to $169 \%$ in case of the wet types. The south-westerly wet types increase the tornado day frequency by more than factor 2.2. And so do the types which are cyclonic in $950 \mathrm{hPa}$ and anticyclonic in $500 \mathrm{hPa}$. 
Similar results have been obtained when considering only the summer months instead of all months of the years. However, due to the smaller sample size results are less significant and not shown here.

\subsection{Tornadoes and thunderstorm days}

As both tornadoes and thunderstorms are local phenomena, their spatial distribution has to be taken into account. For this reason both data sets from 1950 2003 and 1980-2003 have been gridded into a $1^{\circ} \times 1^{\circ}$ latitude-longitude grid. For each $1^{\circ} \times 1^{\circ}$ segment the number of tornadoes over the whole period is counted.
The thunderstorm days per yr are averaged over the climate stations of each segment.

In Fig. 8 the geographical distribution of the tornado frequency, the average thunderstorm days per yr and the average ratio of thunderstorm days per tornado day are displayed for the two periods. The highest number of tornadoes has been observed in the north-western and south-western parts of Germany for all types and both periods. Yet there is a secondary maximum in the eastern part near Berlin. Except from the northwest, the geographical distribution of the tornado reports mainly follows the population density of the country. In the favourite south-western and western regions, obviously
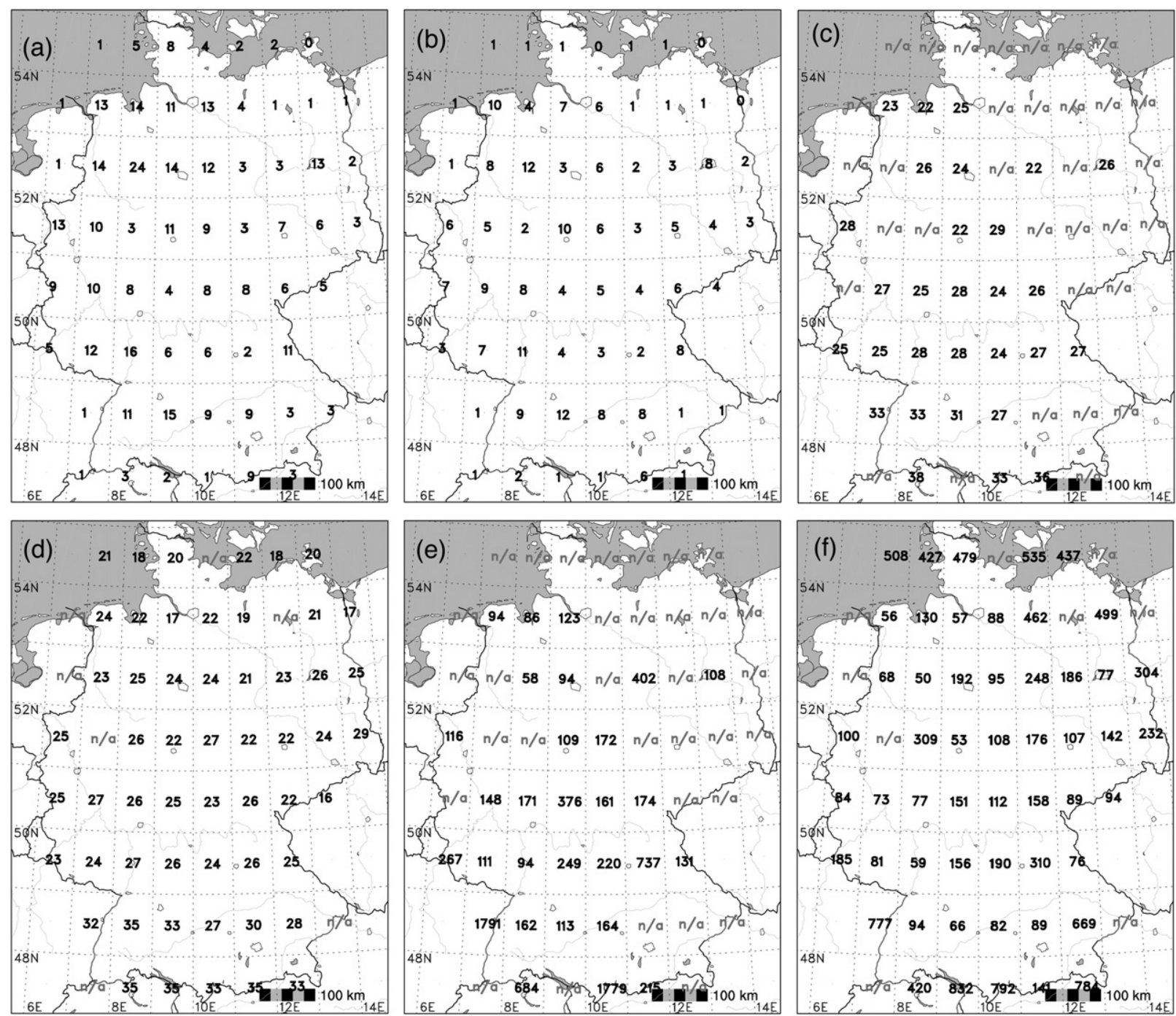

Fig. 8. Geographical distribution of the tornado days 1950-2003 (a) and 1980-2003 (b), average number of thunderstorm days per yr 1950-2003 (c) and 1980-2003 (d), and the average number of thunderstorm days per tornado day in $1^{\circ} \times 1^{\circ}$ latitude-longitude regions $1950-2003$ (e) and $1980-$ 2003 (f). 
one tornado day every second year is presently (assuming the distribution 1980-2003 as present state) very likely. However, there are differences between the spatial distribution of tornadoes and thunderstorms, since the maximum of thunderstorms can be found in the southwest of Germany but not in the northwest. As the thunderstorms are observed regularly by skilled observers of the DWD (although even not all thunderstorm events are observed), the fraction of reported events to those which have really occurred is expected to be higher

\section{(a)}

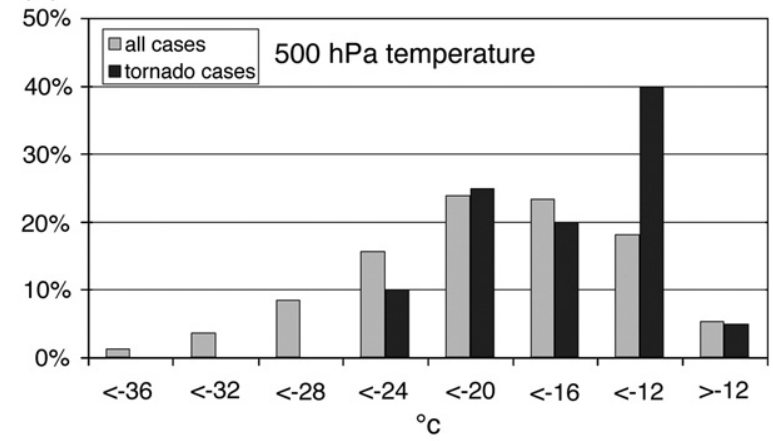

(b)

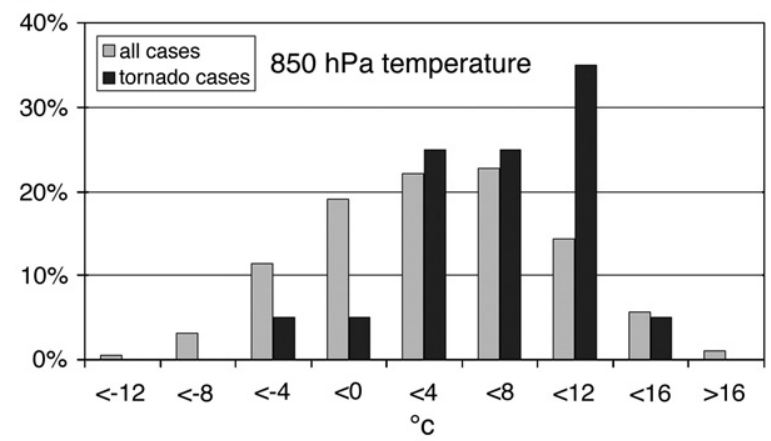

(c)

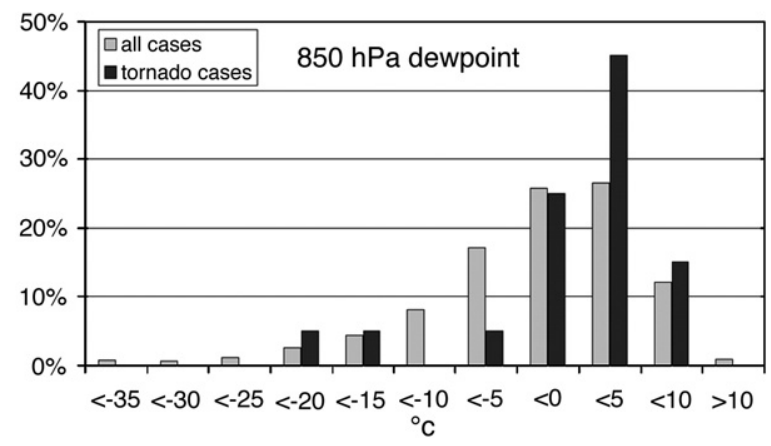

Fig. 9. Frequency distribution of tornado days 1980-2003 in the $1^{\circ} \times 2^{\circ}$ region $51-52^{\circ} \mathrm{N}, 6-8^{\circ} \mathrm{E}$ around the aerological station Essen (Germany) to (a) $500 \mathrm{hPa}$ temperature, (b) $850 \mathrm{hPa}$ temperature, (c) $850 \mathrm{hPa}$ dewpoint, in comparison to the corresponding frequency distribution for all days of the whole period (with and without tornadoes). for thunderstorms compared to tornadoes, especially in areas with low population density. The fraction of thunderstorm days to tornado days displayed in Fig. 8e and $\mathrm{f}$ therefore has to be regarded as a minimum estimation and the spatial distribution has to be interpreted with caution. In north-western Germany $\left(52-53^{\circ} \mathrm{N}, 8-9^{\circ} \mathrm{E}\right)$ this fraction is lowest with $58(1950-2003)$ and 50 (1980-2003), respectively, which means that during 50 thunderstorm days one tornado day has been reported on average in that region. The average number of thunderstorm days per yr in Germany ranges from 16 to $41 \mathrm{~d}$ (1980-2003), e.g. in the city Essen, located in western Germany, there are $30 \mathrm{~d}$.

\subsection{Tornado frequency and aerological parameters}

Finally, a frequency analysis has been carried out for the temperature in 500 and $850 \mathrm{hPa}$ and the dewpoint in $850 \mathrm{hPa}$ as additional atmospheric parameters. Fig. $9 \mathrm{a}-\mathrm{c}$ shows the frequency distributions of these 3 parameters for the tornado days during the period in the region around the aerological station Essen $\left(51-52^{\circ} \mathrm{N}, 6-8^{\circ} \mathrm{E}\right)$ in comparison to the corresponding frequency distribution for all days (with and without tornadoes).

Since most tornadoes occur in summer, there is a shift for the tornado distribution to higher temperature and dewpoint values as expected. However, the remarkable feature for all 3 parameters is that all distributions of the tornado cases have one outstanding maximum, and this maximum can be found for high, but not extremely high values. These are the ranges -16 to $-12{ }^{\circ} \mathrm{C}$ for the $500 \mathrm{hPa}$ temperature, 8 to $12{ }^{\circ} \mathrm{C}$ for the $850 \mathrm{hPa}$ temperature and 0 to $5^{\circ} \mathrm{C}$ for the $850 \mathrm{hPa}$ dewpoint. The frequencies for these ranges are between 35 and $45 \%$. This implies that an increased tornado risk can be expected for values in these ranges if no other information is taken into account.

\section{Discussion}

As tornadoes do not belong to those climate parameters which have been observed regularly over many years, a data basis of occurred tornadoes could never be complete. However, the TorDACH compilation is the most extensive one which is available for Germany and is quality checked. The investigation period of 1950 2003 covers the recent years where the global warming accelerated fast compared to previous years and also the number of reported observations increased, especially for the most recent years of the period. This is in line with the fact that the highest number of tornadoes was reported in the exceptional years 2003 and 2000. 
However, the seasonal cycle of the tornado frequency and also the intensity distribution have not changed considerably during this period 1950-2003.

The results of the analysis of the relation to weather types are consistent with earlier studies (Wegener, 1917; Fuchs, 1978, 1981) and other regions of the world (e. g. Thom, 1963). A preference of humid southwest types is to be expected since the warm humid air which is advected from the Atlantic and the Mediterranean from southwesterly direction to Germany (the "Spanish plume", Morris, 1986), combined with an orogenic low-level wind shear can easily intensify thunderstorms and thus, also lead to tornadoes, especially in summer. From a weather type dependent spatial analysis of precipitation data of Germany (Bissolli and Müller-Westermeier, 2005) we know that these types can cause higher precipitation amounts especially in the south-western and western parts of the country where also most of the tornadoes are reported. This would suggest that these spatial maxima are perhaps real and only partly due to a higher population density in these areas. The significance tests have shown that the preference of southwest wet types for tornado occurrence has likely not appeared by chance.

The geographical distribution of thunderstorms differs in some respect from that of tornadoes. Clearly one has to consider that thunderstorms have been observed with more reliability than tornadoes. However, as tornadoes can be observed only on a few of all thunderstorm days ( 1 out of 50 or less) such differences should not surprise. For the United States, higher ratios of 1-10 thunderstorm days per tornado were found and a significant positive correlation between these two quantities (Yarbrough and Meentemeyer, 1978). Thunderstorms indicate strong convective activity as well as tornadoes but because of their different frequencies they cannot serve as the only criterion for tornado occurrence. Like tornadoes, they are not predictable in the long-term. For prediction, in particular for climate prediction and analysis, it seems a better approach to use characteristic large-scale weather situations instead of local phenomena.

The observation of audible thunder as definition of thunderstorm days is not without problems. It does not matter how far the thunderstorm is away from the observing station, but in general, the thunder can be heard up to a distance of about $15 \mathrm{~km}$, depending on the background noise. From this definition it is very likely that some of the thunderstorms are not observed when they are too far away from the next observing station or when they are not heard by the observer if other kind of noise occurs at the same time. However, this is the climate information which is available for a longer period, and since there is a spatially well-distributed network of climate stations available within Germany (all parts of Germany, lower and higher altitudes, mountainous and coastal regions), there is consistency and a certain reliability of this data set to be expected.

The weather types classification criteria can certainly be refined by other meteorological quantities as we tried it for temperature and dewpoint in $850 / 500 \mathrm{hPa}$. These are clearly not the only useful parameters. Other quantities or derived indices might show more appropriate results. Rasmussen and Blanchard (1998) proposed a number of dynamical parameters, especially for strong tornadoes in supercells, although it turned out to be quite difficult to describe the complex supercell dynamics (e.g. the rear-flank downdraft) by such parameters. However, a change of the frequency distribution could be seen even from the simple parameters presented here.

\section{Conclusions and outlook}

The following relations between tornado reports and weather types occurrence have been found:

- The objective weather types classification has turned out to be a useful tool for identifying characteristic weather situations for such extreme events.

- The frequency of tornado days depends significantly on the weather type.

- South-westerly and wet weather types enhance the tornado frequency considerably.

- Thunderstorm days and precipitable water do not appear to be useful tornado predictive parameters.

By extending the weather types classification to the future (it still runs operationally every day) and also to the past (by using e.g. reanalysis data of appropriate data sets, e.g. the ERA-40 data set), such an analysis could be extended to a longer time period which is long enough to detect possible changes of weather type impact with time.

The development of further climate indices is promising and could help us to make a step further in climatological tornado forecasting. After having found clear dependencies of tornado frequencies on a certain set of climate indices, these relations could be used directly by the weather forecaster. The tornado probability for a particular weather type in combination with local conditions, given by certain climate index values, could be estimated from the climatological tornado frequency distribution, and if the frequency in a given case exceeds a threshold, tornado advisory or watches could be issued for a certain region. 
For climatological evaluation like in the present paper, or as by Dotzek et al. (2005), it would be highly beneficial if a homogeneous and consistent database of tornadoes and other severe storm phenomena were available all over Europe. The reason for this is quite obvious: even if climate models were able to predict changes in occurrence of extreme, dangerous events like tornadoes, we would still have to rely on statistical-climatological analyses for validation and a consequent monitoring of this phenomenon. Linking the weather type to the tornado monitoring information can serve as an additional basis for further climatological evaluation and risk assessment as well as for forecast and warning verification case studies. The recent development of the European Severe Weather Database ESWD (www.essl.org/ESWD/) was an important step to improve the database situation in Europe. The German TorDACH data until the end of 2005 have already been converted to ESWD format, and from 2006 on, severe local storm reports from Germany and other European countries only go to the ESWD database.

\section{Acknowledgements}

The authors are grateful to Dr. Ernst Dittmann (DWD, now in retirement) for initiating this analysis as a contribution in tornado climatology. Also we are very grateful to Martin Beniston who gave us the opportunity to present our results on a poster at the EGU conference in Vienna in April 2005 and invited us to submit this paper for this special issue. The manuscript was kindly reviewed by two anonymous reviewers who provided many valuable recommendations for an improvement of our paper.

\section{References}

Bissolli, P., Dittmann, E., 2001. The objective weather types classification of the German Weather Service and its possibilities of application to environmental and meteorological investigations. Meteorol. Z. 10 (4), 253-260.

Bissolli, P., Müller-Westermeier, G., 2005. The spatial distribution of precipitation in Germany for different weather types. Submitted to European Cooperation in the Field of Scientific and Technical Research (COST), Action 733.

Brooks, H.E., 2000. The climatology of severe thunderstorms: what we can know. Preprints 20th Conf. on Severe Local Storms, Orlando. Amer. Meteor. Soc., Boston, pp. 126-129.

Brooks, H.E., Doswell, C.A., 2001a. Normalised damage from major tornadoes in the United States: 1890-1999. Weather Forecast. 16, $168-176$.

Brooks, H.E., Doswell, C.A., 2001b. Some aspects of the international climatology of tornadoes by damage classification. Atmos. Res. $56,191-202$.
Cole, J.N.S., Barker, H.W., Randall, D.A., Khairoutdinov, M.F., Clothiaux, E.E., 2005. Global consequences of interactions between clouds and radiation at scales unresolved by global climate models. Geophys. Res. Lett. 32, L06703. doi:10.1029/2004GL020945.

Doswell, C.A., Burgess, D.W., 1988. On some issues of United States tornado climatology. Mon. Weather Rev. 116, 495-501.

Doswell, C.A., Brooks, H.E., Maddox, R.A., 1996. Flash flood forecasting: an ingredients-based methodology. Weather Forecast. $11,560-580$.

Dotzek, N., 2001. Tornadoes in Germany. Atmos. Res. 56, 233-251.

Dotzek, N., 2002. Severe local storms and the insurance industry. J. Meteorol. 26, 3-12 (available at tordach.org).

Dotzek, N., 2003. An updated estimate of tornado occurrence in Europe. Atmos. Res. 67-68, 153-161.

Dotzek, N., Berz, G., Rauch, E., Peterson, R.E., 2000. Die Bedeutung von Johannes P. Letzmanns "Richtlinien zur Erforschung von Tromben, Tornados, Wasserhosen und Kleintromben" für die heutige Tornadoforschung (The relevance of Johannes P. Letzmann's "Guidelines for research on tornadoes, waterspouts, and whirlwinds" for contemporary tornado research). Meteorol. Z. 9, 165-174 (in German, available at tordach.org).

Dotzek, N., Grieser, J., Brooks, H.E., 2003. Statistical modelling of tornado intensity distributions. Atmos. Res. 67-68, 163-187.

Dotzek, N., Kurgansky, M.V., Grieser, J., Feuerstein, B., Névir, P., 2005. Observational evidence for exponential tornado intensity distributions over specific kinetic energy. Geophys. Res. Lett. 32, L24813. doi:10.1029/2005GL024583.

Feuerstein, B., Dotzek, N., Grieser, J., 2005. Assessing a tornado climatology from global tornado intensity distributions. J. Climate 18, 585-596.

Fuchs, D., 1978. Über das Auftreten von Tornados in der BRD in Abhängigkeit von synoptischen und aerologischen Bedingungen (On the occurrence of tornadoes in the FRG, depending on synoptic and aerological conditions). Referendararbeit GeophysBDBw. 56 pp. (in German).

Fuchs, D., 1981. Gefährdung des Tiefflugs durch Tornados (Tornado hazard to low-flying aircraft). Promet 81 (4), 8-10 (in German).

Fujita, T.T., 1981. Tornadoes and downbursts in the context of generalised planetary scales. J. Atmos. Sci. 38, 1511-1534.

Fujita, T.T., 1992. Mystery of Severe Storms. Chicago University Press, Chicago. 298 pp.

Fulks, H.W., 1969. A synoptic review of the Pforzheim tornado of 10 July 1968. Techn. Bull. 2D Weather Wing, Air Weather Serv., US Air Force Apr. 1969, pp. 26-43.

Hubrig, M., 2004. Analyse von Tornado- und Downburst-Windschäden an Bäumen (Analysis of tornado and downburst wind damage to trees). Forst Holz 59, 78-84 (in German, available at tordach.org).

IPCC (Ed.), 2001. Climate Change 2001 - The Scientific BasisCambridge University Press, Cambridge. $881 \mathrm{pp}$.

Morris, R.M., 1986. The Spanish plume - testing the forecaster's nerve. Meteorol. Mag 115, 349-357.

Nestle, R., 1968. Der Tornado vom 10.7.1968 im Raum Pforzheim. Meteorol. Rundsch. 22 (1), 1-3.

Ostby, F.P., 1999. Improved accuracy in severe storm forecasting by the Severe Local Storms Unit during the last 25 years: then versus now. Weather Forecast. 14 (4), 526-543.

Rasmussen, E.N., Blanchard, D.O., 1998. A baseline climatology of sounding-derived supercell and tornado forecast parameters. Weather Forecast. 13 (4), 1148-1164.

Schmitz, M.E., 2005. Tornados in Deutschland (Tornadoes in Germany). Diplomarbeit, Fachbereich VI Geographie/Geowissenschaften, Universität Trier. 115 pp. (in German). 
Snow, J.T. (Ed.), 2001. Special Issue: Conference on European Tornadoes and Severe Storms. Atmos. Res., vol. 56(1-4). 409 pp. Snow, J.T. (Ed.), 2003. Special Issue: European Conference on Severe Storms 2002. Atmos. Res., vol. 67-68. 703 pp.

Thom, H.C.S., 1963. Tornado probabilities. Mon. Weather Rev. 91 (10), $730-736$

Tveito, O.E., Ustrnul, Z., 2003. A review of the use of large-scale atmospheric circulation classification in spatial climatology. DNMI Report 10/03 Klima (available at DNMI, the Norwegian Met. Service)

Verbout, S.M., Brooks, H.E., Leslie, L.M., Schultz, D.M., 2006. Evolution of the U.S. tornado database: 1954-2003. Weather Forecast. 21, 86-93.
Wegener, A., 1917. Wind- und Wasserhosen in Europa (Tornadoes in Europe). Verlag Friedrich Vieweg und Sohn, Braunschweig. 301 pp. (in German, available at essl.org).

Yarbrough Jr., J.W., Meentemeyer, V., 1978. Seasonal and regional variation in the correlation of thunderstorm days with tornado frequency. J. Appl. Meteorol. 17, 1741-1746.

Yarnal, B., Comrie, A.C., Frakes, B., Brown, D.P., 2001. Review: developments and prospects in synoptic climatology. Int. J. Climatol. 21, 1923-1950. 